\title{
Maternal and Child Level Factors Associated with Childhood (0-23 months) Diarrhoea in Ghana: A Pooled Analysis of National Representative Datasets
}

\author{
Anthony Mwinilanaa Tampah-Naah \\ Department of Environment and Resource Studies, \\ University for Development Studies, Ghana \\ E-mail: atampah@uds.edu.gh \\ DOI//http://dx.doi.org/10.4314/gjds.v16i2.8
}

\begin{abstract}
In Ghana, diarrhoea is one of the leading causes of childhood morbidity and mortality. The objective of this study was to examine maternal and child level factors associated with diarrhoea among children in Ghana. A weighted group of 4,821 mother-child dyads was used for the analysis. The analysis was restricted to mothers with children under 2 years of age. Multivariate logistic regression analysis was performed on the pooled data. The pooled prevalence of diarrhoea among the children was 18 per cent. It was found that children older than five months, rural children, children whose mothers had 24 months or more preceding birth interval, and those houses' floors made of unimproved materials were more likely to have had experienced diarrhoea. While children with mothers who obtained secondary or higher education and those had access to unimproved sources of drinking water reported less occurrence of diarrhoea. Maternal and child factors have some effects on the occurrence of diarrhoea among children less than two years in Ghana. To decrease the prevalence of childhood diarrhoea in the country, more educative programmes are required for mothers whose children are more likely to having frequent episodes of diarrhoea.
\end{abstract}

Keywords: Maternal, Child, Factors, Diarrhoea, Ghana, Survey

\section{INTRODUCTION}

Diarrhoea is a leading cause of childhood morbidity and mortality worldwide (World Health Organisation [WHO], 2015). This disease accounted for the deaths of 5.9 million children under-five years in 2015; that is translating to approximately 
16,00o deaths every day. Most of these deaths occurred in the African region with mortality rate of above 100 deaths per 1,000 live births (United Nations Children's Fund [UNICEF], 2015). Projections show that diarrhoea contributed to about nine per cent of all deaths among children under age five; thus being the second highest cause of childhood mortality; and approximately 1,400 young children dying each day and 526,000 children per year worldwide (UNICEF, 2015).

Predictably, 8o per cent of these deaths occur in some developing countries where living conditions are mostly unfavourable for the growth and development of children (Boschi-Pinto, Velebit \& Shibuya, 2008). The achievement of related Sustainable Development Goal 3 (target 3.2 - under-5 mortality to at least as low as 25 per 1,00o live births) (United Nations [UN], 2016) would be a mirage if this pattern of mortality continues unabated. Also, an assessment of national survey reports in Ghana indicates that the prevalence of diarrhoea in 2008 was $19.8 \%$ and dropped to $12 \%$ in 2014 (Ghana Statistical Service [GSS], Ghana Health Service [GHS], \& ICF Macro, 2009; 2015). But diarrhoea is still documented among the top five childhood diseases in the country.

The consumption of contaminated fluids or foods by infants and children (Lamberti, Walker, Noiman, Victora, \& Black, 2011; Agustina, Sari, Satroamidjojo, BoveeOudenhoven, Feskens, \& Kok, 2013) and the abysmally ineffective interventions have been identified by studies (Agustina, Sari, Satroamidjojo, Bovee-Oudenhoven, Feskens, \& Kok, 2011; WHO and UNICEF, 2013) to be the major contributory factors to high prevalence of diarrhoea especially in some developing countries. Aside these nutritional lapses and unproductive interventions, maternal and child level factors may play critical core roles to the occurrences of childhood diarrhoea.

There has been an array of research articles published on the factors linked to childhood diarrhoea (Gebru, Taha \& Kassahun, 2014; Thiam, Diene, Fuhrimann, Winkler, Sy, Ndione, et al., 2017). Most of these articles focused on children underfive years. Although this segment of children is equally prone to infectious diseases like diarrhoea, it has been argued that children less than two year bear much burden of diarrhoea cases (Pathela, Hasan, Roy, Huq, Siddique \& Sack, 2006; WHO, 2009). This group of children mostly referred to as infants and young children are in a critical period of their growth and development that makes them highly susceptible to experiencing diarrhoea (UNICEF \& WHO, 2009).

The study, therefore, aimed to examine maternal and child level factors associated with diarrhoea among children (0-23 months). This was achieved by using pooled data from Ghana Demographic and Health Surveys of the years 2003, 2008, and 2014. Findings of this study would contribute to the argument on the factors 
associated with diarrhoea especially among children aged 0-23 months in developing countries.

\section{Context of the Study}

The population of Ghana is approximately 27 million people with urban and rural populations of 56 percent and 44 percent respectively. Averagely, the total fertility rate is 4.03 and in relation to place of residence, TFR in rural areas is 4.4 while in urban areas it is 3.1. Children under-five in the country constitute about 15 percent (GSS, 2019). To cater for health needs of, but not limited to, children in the country, a number of health facilities have been and continue to be provided. There are about 5,421 community-based health planning and services (CHPS) compounds, 998 clinics, 140 district hospitals and 1004 health centres distributed across the various administrative regions in the country (GHS, 2018).

In Ghana, diarrhoea is one of the major causes of morbidity and mortality among children under-five (Ameyaw, Ameyaw, Acheampong \& Appiagyei, 2017). Outpatient diarrhoea morbidity cases in the country across the years were: 1,515,189 in 2015; 1,570,557 in 2016; and 1,429,990 in 2017 (GHS, 2018). Factors accounting for these episodes of childhood diarrhoea are generally linked to dietary and environmental conditions (Ameyaw et al., 2017). The Ghana Health Service, with support from the Government of Ghana and other international organizations such as UNICEF, has implemented tailor-made interventions in areas of exclusive breastfeeding to 6 months, and access to clean water, sanitation and promotion of hygiene (GHS 2016).

\section{Theoretical and Conceptual Frameworks}

The analytical child survival framework by Mosley and Chen (2003) was reviewed (framework not shown). It consists of both social and biological variables to measure mortality and morbidity. It is based on the premise that all social and economic determinants of child mortality necessarily operate through a common set of biological mechanisms, or proximate determinants to exert an impact on mortality. What makes the framework essentially useful is that it fuses both approaches by social and medical scientists by considering three components to assess a single health outcome (mortality or morbidity). These components are independent (thus at the individual-level, household-level, and community-level), proximate, and dependent variables. The framework could inform social scientists or epidemiologists on the conceptualization of models (Hill, 2003). 
In the framework, proximate determinant measures are environmental conditions, health care practices, feeding practices, and disease states that act mutually to determine the survival of a child. The vertical interaction of the independent variables and the proximate determinants would define the health status of a child as either healthy or sick. And the rate of recovery or the progression of illness is attributed to personal illness control variables. The personal illness control measures for a child are pre-determined by the independent variables. The dependent variable (state of health) measures a single outcome (sickness) and further describes either the growth faltering (dietary deficiency) or mortality rates in a cohort of children. To adequately assess the health outcomes of a child, the framework proposes a combination of the two states of sickness (growth faltering and mortality).

In adapting the Mosley and Chen's framework in this study, four levels of variables were considered (individual, community, health, and environmental) (Figure 1). The individual variables included age of child, sex of child, maternal age, marital status, maternal education, and work status. With community-level variables, the study incorporated place of residence. Health level variables consisted of preceding birth interval, and antenatal care visits. Environmental variables included source of drinking water, type of toilet, and floor material. The health and environmental variables were treated as proximate determinants. Therefore, the individual and community level variable considered as independent variables. The horizontal interactions of the independent variables, are important but do not independently contribute to a health outcome. This is because the independent variables require a mechanism or an intermediary to operate in order to determine a child's health status, and proximate determinants are the mechanisms. 


\section{Figure 1: Conceptual framework}

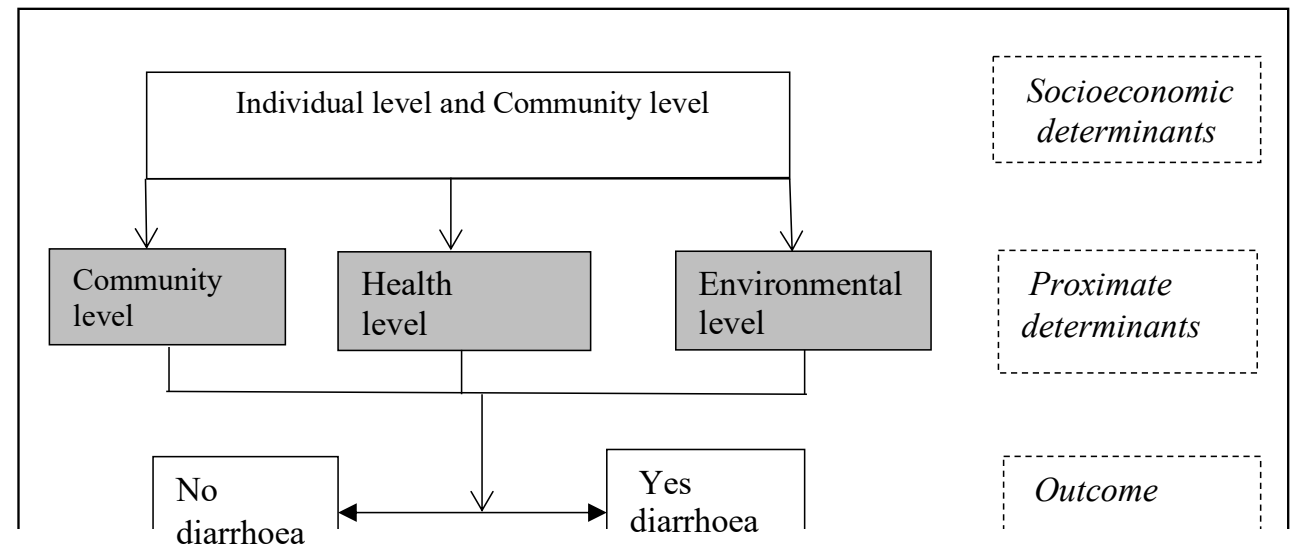

Source: Author's construct (adapted from Mosley and Chen, 2003)

\section{METHODS}

\section{Study Data}

The study used data from Ghana and Demographic Health Surveys (GDHS). More information about the surveys can be found at https://dhsprogram.com. The specific data used in this study were from the GDHS 2003, 2008 and 2014 individual datasets. These datasets contain data on women, and issues related to children. Analyses were restricted to mothers (15-49 years) who had a children less than two years of age (o-23 months) at the time of the survey. A weighted group of 4675 mother-child pairs was used for the analyses. The GDHS datasets are publicly available at $h$ ttp://dhsprogram.com/data/dataset/Ghana

\section{Dependent Variable}

The dependent variable for the study was diarrhoea (all forms of it). In each of the GDHS (2003, 2008, and 2014) mothers were asked whether any of their children had diarrhoea during the two weeks preceding the survey. The question on diarrhoea was posed as "Has (NAME) had diarrhoea in the last 2 weeks?" And the responses to this question were: 'No =o'; 'Yes, last two weeks =1'; 'Don't know = 8'. Only the 'No' and 'Yes' responses were used in the present study. This was done to avoid bias results in the multivariate analysis. 


\section{Independent Variables}

The independent variables selected for this study were informed by the review of related literature. Some of the variables were recoded while others were adapted as reported in the GDHS reports. These selected maternal and child level variables were put into four groups - individual level (age of child, sex of child, maternal age, marital status, maternal education, work status), community level (place of residence); health level (preceding birth interval, antenatal visits); and environmental level (source of drinking water, type of toilet facility, type of floor material).

Age of child [in months] was recoded into 0-5, 6-11, and 12-23. Studies have indicated that children at different ages tend to be exposed to varying levels of diarrhoea (Mihrete, Alemie, \& Teferra, 2014; Tambe, Nzefa \& Nicoline, 2015; Getachew, Guadu, Tadie, Gizaw, Genrehiwot, et al., 2018). Literature has further demonstrated that younger children (o-5 months) are less prone to diarrhoeal infections compared to older children (6 months and above) (Stanly, Sathiyasekaran \& Palani, 20o9; Gedefaw \& Berhe, 2015). Maternal education was categorised into no education, primary, and secondary or higher. The educational level of a mother may enable her to make informed decisions on how to cater for her child to avert diarrhoea (KumiKyereme \& Amo-Adjei, 2016; Tambe et al., 2015).

Maternal work status responses were put into not working, and working. Also, the work status of a mother may influence how she would provide a conducive environment for her child to minimise the occurrence of diarrhoea (Gebru, Taha \& Kassahun, 2014; Pinzon-Rondon, Zarate-Ardila, Hoyos-Martinez, Ruiz-Sternberg \& Velez-van-Meerbeke, 2015). In terms of place of residence, mothers were put into two groups (urban and rural). Literature has suggested that the environment in which children live could predispose them to some episodes of diarrhoea (KumiKyereme \& Amo-Adjei, 2016; Pruss-Ustun, Bartram, Clasen, Colford, Cumming, Curtis, et al., 2014; Mengiste, Berhane \& Worku, 2013; Siziya, Muula \& Rudatsikira, 2013).

For preceding birth interval, births of mothers were recoded into those who had less than 24 months and those of 24 months or more. Studies indicate that preceding birth interval of mothers could either offer them enough time or less time to adequately cater for their children (Fotso, Cleland, Mberu, Mutua \& Elungata, 2013; Pirincci, Tasdemir, \& Oguzoncul, 2016; Rasooly, Saeed, Noormal et al., 2013). During antenatal visits, mothers are counselled on best practices in areas of child care including ways to prevent the occurrence of diarrhoea among their children (McGlynn, Wilk, Luginaah \& Ryan, 2015). This variable was coded as zero visit, 1-7 
visits and 8 visits or more. This categorization is in conformity with the new WHO recommendations on Antenatal care (WHO, 2016).

Environmental variables included in the analysis were source of drinking water, type of toilet facility, and type of floor material. The first two variables are considered as 'Siamese-twins' that potentially influence the occurrence of diarrhoea among children (Hunter, Risebro, Yen, Lefebvre, Lo, Hartemann et al., 2013; Plate, Strassmann \& Wilson, 2004; WateAid, 2017; Carr, 2001; Mohammed \& Zungu, 2016; Degebasa, Weldemichael \& Marama, 2018; Aziz, Ahmad, Abdul Razak, Omar, Kasim, Yusof et al., 2018). Also, the type of floor material of households could determine the level of presence of diarrhoea causing pathogens that children may come into contact with (Exum, 2016; Hashi, Kumie \& Gasana, 2016; Bado, Susuman, and Nebie, 2016). Mothers in the survey were asked about the type of each of the selected environmental issues they used or had in their various houses.

The various responses given by mothers, in the aforementioned variables, were recoded as either 'improved' or 'unimproved'. In relation to source of drinking water, responses were categorised as follows: improved sources (piped into dwelling, piped to yard/plot, public tap or standpipe, tube-well or borehole, protected well, protected spring, rainwater); and unimproved sources (unprotected spring, unprotected well, river/dam/lake/ponds/stream/canal/irrigation, tanker-truck, cart with small tank, bottled water sachet).

For type of toilet facility, improved facilities included flush to piped sewer system, flush to septic tank, flush to pit latrine, flush to somewhere else, ventilated improved pit latrine (VIP), pit latrine with slab, composting toilet, and a special case (i.e., flush/pour flush of excreta to a place unknown to the respondent); and unimproved facilities consisted of flush/pour flush to elsewhere (such as street, yard/plot, open sewer or a ditch), pit latrine without slab, bucket, hanging toilet or hanging latrine, shared sanitation, no facilities, bush or field. The above categorizations are in accordance to WHO and UNICEF Joint Monitoring Programme (JMP) for Water and Sanitation (WHO and UNICEF, 2018).

Further, type of floor material was grouped as improved (tablets/wood/planks, palm/bamboo, mat, adobe, parquet/polished wood, vinyl/asphalt strips/ floor mat, linoleum, ceramic tiles/mosaic, cement, carpet, stone, bricks); and unimproved (earth, sand, clay, mud, dung); in accordance with Demographic and Health Surveys (DHS) Program (Florey \& Taylor, 2016). A variable, 'survey year', was created to further assess the occurrence of diarrhoea among children across the three years. 


\section{Data Analysis}

Cross-tabulations showing frequencies and proportions between the dependent and the independent variables were indicated. Further, chi-square test of independence was applied to ascertain the association between the independent variables and the occurrence of diarrhoea. Moreover, multilevel logistic regressions models in accordance with the argument embedded in the study's conceptual framework that proximate variables may influence the relationship between independent variables and the outcome variable were assessed. The models were equally used to estimate the margin of effects among the variables to ensure generalization of the findings. Statistical significance was assessed by using a $p$-value of 0.05 . Results were presented in odds ratios and 95\% Confidence Interval (CI). Only independent variables that had a $p$-value less than 0.25 were considered for the logistic regression. STATA (version 12.0) was used to process the data. At each stage of the data analyses, a STATA survey set statement (svy prefix command) was used to produce unbiased means and accurate variance estimates. A survey design weight of voo5, primary sampling unit of vo21 and strata of vo23 were used in the survey set statement.

\section{RESULTS}

Table 1 indicates that the pool prevalence of diarrhoea was 18 per cent. Among the survey years used for the study, the prevalence of diarrhoea was highest (25\%) in 2008 and the lowest rate (13\%) recorded in 2014.

Table 1: Prevalence of diarrhoea

\begin{tabular}{|l|l|l|}
\hline \multirow{2}{*}{ Survey year } & Diarrhoea & \multicolumn{2}{|l|}{} \\
\cline { 2 - 3 } & No diarrhoea & Yes diarrhoea \\
\hline 2003 & $1115(80.90)$ & $263(19.10)$ \\
\hline 2008 & $876(74.90)$ & $294(25.10)$ \\
\hline 2014 & $1966(86.51)$ & $307(13.49)$ \\
\hline Pooled & $3958(82.09)$ & $863(17.91)$ \\
\hline
\end{tabular}

Source: Field survey, 2016

Table 2 shows that age of child, maternal education, residence, preceding birth interval, source of drinking water, type of toilet facility and type of floor material were statistically associated with the occurrence of diarrhoea.

Children older than five months were found to have recorded higher cases of diarrhoea. Prevalence of diarrhoea was highest among children aged 12-23 months (23\%) and the lowest prevalence was among infants 0-5 months (7\%). Marginal 
difference was observed for episodes of childhood diarrhoea between categories of sex of child and among those of maternal age. A similar pattern was noticed between children whose mothers never married and those who ever married. Two-fifth of children whose mothers had no education (21\%) and 15 per cent of those with secondary or higher levels of education reported episodes of diarrhoea. Also, the proportion of diarrhoea among children in rural areas was 20 per cent compared with 15 per cent in urban areas. Nineteen per cent prevalence of diarrhoea was reported for children whose mothers had 24 months or more preceding birth intervals and 15 per cent for children whose mothers had less than 24 months birth intervals. A lesser proportion of mothers (15\%) had recommended number of antenatal visits.

The prevalence of diarrhoea was higher among children with mothers who had access to improved source of drinking water (19\%) compared with those who had access to unimproved source of drinking water (15\%). A higher proportion of diarrhoea was linked with children whose mothers had access to unimproved toilet facilities (22\%) than those who had access to improved toilet facilities (16\%). With type of floor material used, about two in ten children with mothers whose house floors were made from unimproved materials had diarrhoea (Table 2).

Table 2: Maternal characteristics and prevalence of diarrhoea among children less than two years

\begin{tabular}{|l|l|l|l|}
\hline \multirow{2}{*}{ Maternal characteristics } & \multicolumn{2}{|l|}{ Had Diarrhoea recently } \\
\cline { 2 - 4 } & Frequency & Proportion & Pearson $\chi^{2}$ \\
\hline Individual level & & & \\
Age of child (mean=11.3; SD=6.6) & 79 & 6.59 & 0.000 \\
o-5 & 249 & 19.69 & \\
6 6-11 & 535 & 22.73 & \\
$12-23$ & & & \\
\hline Sex of child & & & \\
Male & 447 & 18.12 & \\
Female & 417 & 17.69 & \\
\hline Maternal age (mean=29.2; SD=6.9) & & & \\
15-19 & 55 & 17.66 & \\
20-34 & 603 & 17.79 & \\
35-49 & 206 & 18.35 & \\
\hline Marital status & & & \\
Never married & 62 & 19.40 & \\
Married & 619 & 18.31 & \\
Living with partner & 139 & 15.42 & \\
Ever married & 42 & 20.05 & \\
\hline
\end{tabular}




\begin{tabular}{|c|c|c|c|}
\hline \multirow[t]{2}{*}{ Maternal characteristics } & \multicolumn{3}{|c|}{ Had Diarrhoea recently } \\
\hline & Frequency & Proportion & Pearson $\chi^{2}$ \\
\hline $\begin{array}{l}\text { Maternal education } \\
\text { No education } \\
\text { Primary } \\
\text { Secondary/higher }\end{array}$ & $\begin{array}{l}316 \\
202 \\
346 \\
\end{array}$ & $\begin{array}{l}20.58 \\
19.65 \\
15 \cdot 31 \\
\end{array}$ & 0.000 \\
\hline $\begin{array}{l}\text { Work status } \\
\text { Not working } \\
\text { Working }\end{array}$ & $\begin{array}{l}164 \\
699 \\
\end{array}$ & \begin{tabular}{|l|}
16.94 \\
18.16 \\
\end{tabular} & 0.012 \\
\hline $\begin{array}{l}\text { Community level } \\
\text { Residence } \\
\text { Urban } \\
\text { Rural }\end{array}$ & $\begin{array}{l}295 \\
568\end{array}$ & $\begin{array}{l}15.28 \\
19.67\end{array}$ & 0.001 \\
\hline $\begin{array}{l}\text { Health level } \\
\text { Preceding birth interval } \\
\text { Less than } 24 \text { months } \\
24 \text { months or more }\end{array}$ & $\begin{array}{l}375 \\
614\end{array}$ & $\begin{array}{l}15.36 \\
18.56\end{array}$ & 0.165 \\
\hline $\begin{array}{l}\text { Antenatal care visits } \\
\text { o visit } \\
1-7 \text { visits } \\
8 \text { visits or more }\end{array}$ & $\begin{array}{l}37 \\
607 \\
182 \\
\end{array}$ & $\begin{array}{l}18.61 \\
18.77 \\
15.35 \\
\end{array}$ & 0.244 \\
\hline $\begin{array}{l}\text { Environmental level } \\
\text { Source of drinking water } \\
\text { Improved } \\
\text { Unimproved }\end{array}$ & $\begin{array}{l}550 \\
218\end{array}$ & $\begin{array}{l}18.81 \\
15.03\end{array}$ & 0.024 \\
\hline $\begin{array}{l}\text { Type of toilet } \\
\text { Improved } \\
\text { Unimproved }\end{array}$ & $\begin{array}{l}479 \\
383 \\
\end{array}$ & $\begin{array}{l}15.69 \\
21.79 \\
\end{array}$ & 0.000 \\
\hline $\begin{array}{l}\text { Floor material } \\
\text { Improved } \\
\text { Unimproved }\end{array}$ & $\begin{array}{l}646 \\
217\end{array}$ & $\begin{array}{l}17.32 \\
19.97\end{array}$ & 0.078 \\
\hline $\begin{array}{l}\text { Survey year } \\
2003 \\
2008 \\
2014\end{array}$ & $\begin{array}{l}263 \\
294 \\
307 \\
\end{array}$ & $\begin{array}{l}19.10 \\
25.10 \\
13.49\end{array}$ & 0.000 \\
\hline
\end{tabular}

$N=4830$

\section{Factors Associated with Childhood Diarrhoea}

Four multivariate logistic regression models were estimated to examine the likelihood of childhood diarrhoea among children (o-23 months) (Table 3). Model 
I contains individual level variables (age of child, sex of child, maternal education, and maternal work status). At this initial stage, age of child and maternal education gained statistical significance. Children between ages of 6-11 and 12-23 months had higher odds of being sick with diarrhoea. Between these two age groups, children aged 12-23 months ( $\mathrm{OR}=4.257,95 \% \mathrm{CI}=3.303,5.486)$ were about four times more likely to have had diarrhoea cases compared to children aged o-5 months. Also, children whose mothers had secondary or higher education were negatively associated with diarrhoea. Thus, children whose mothers attained secondary or higher formal education ( $\mathrm{OR}=0.674,95 \% \mathrm{CI}=0.537$, 0.848) were less likely to have reported diarrhoea episodes compared to those whose mothers had no formal education.

In Model II, a community level variable (place of residence) was included in the hierarchical model. The variables that were statistically significant $(\mathrm{p}<0.05)$ were age of child, maternal education, and place of residence. Children who were aged 12-23 months were still more than four times likely to have diarrhoea compared to children aged o-5 months. The odds of reported cases of childhood diarrhoea increased marginally for mothers who had secondary or higher education. Further, children with mothers in rural areas (OR $=1.267,95 \% \mathrm{CI}=0.989,1.625)$ had slightly higher likelihood of diarrhoea episodes compared to those in urban areas.

Model III consists of the health level variables (antenatal visits and preceding birth interval). Preceding birth interval variable obtained some statistical significance. None of the newly added variables was significant at this phase. Once again, age of child, maternal education, and place of residence exhibited statistical significance $(p<0.05)$ with diarrhoea. Minimal variations of odds were observed. Likelihood for the occurrence of diarrhoea decreased slightly for children aged 12-23 months, increased marginally for children whose mothers had secondary or higher education, and those were in urban areas.

In the final model (Model IV), the last group of the independent variables (source of drinking water, type of toilet facility, and type of floor material) were added. In this model, there were either marginal reductions or increments in odds of the various categories of variables compared to what was observed in Model III. In this model, preceding birth interval became significant. Children whose mothers had 24 months or more birth interval $(O R=1.339,95 \%$ CI $=0.971,1.846)$ had a little higher possibility of experiencing diarrhoea compared to their counterparts who had less than 24 months birth intervals. All the new variables introduced in Model IV exhibited some statistical significance. Children whose mothers had accessed unimproved sources of drinking water ( $\mathrm{OR}=0.733,95 \% \mathrm{CI}=0.580,0.926)$ were observed to have less reported cases of diarrhoea compared to those whose mothers 
used improved sources of water. Children whose mothers had access to unimproved toilet facilities ( $\mathrm{OR}=1.383,95 \% \mathrm{CI}=1.075,1.777)$, and those whose house floors were made of unimproved materials ( $\mathrm{OR}=1.265,95 \% \mathrm{CI}=0.988,1.619)$ were more likely to have had diarrhoea compared to their respective matching groups.

Table 3: Multiple logistic regression models for factors associated with diarrhoea

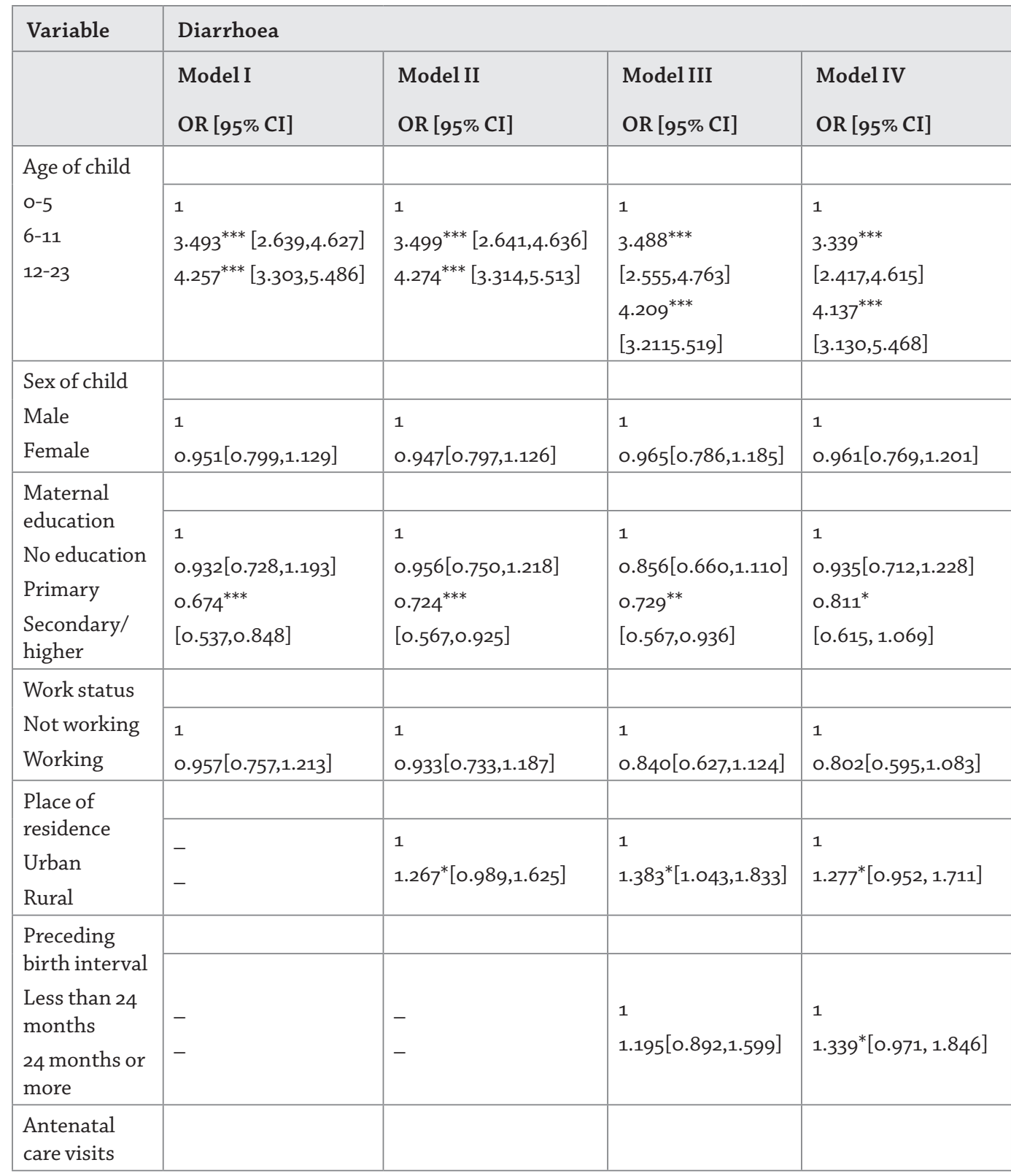




\begin{tabular}{|c|c|c|c|c|}
\hline \multirow[t]{2}{*}{ Variable } & \multicolumn{4}{|l|}{ Diarrhoea } \\
\hline & $\begin{array}{l}\text { Model I } \\
\text { OR [95\% CI] }\end{array}$ & $\begin{array}{l}\text { Model II } \\
\text { OR [95\% CI] }\end{array}$ & $\begin{array}{l}\text { Model III } \\
\text { OR [95\% CI] }\end{array}$ & $\begin{array}{l}\text { Model IV } \\
\text { OR [95\% CI] }\end{array}$ \\
\hline $\begin{array}{l}\text { o visit } \\
1-7 \text { visits } \\
8 \text { visits or } \\
\text { more }\end{array}$ & $\begin{array}{l}- \\
- \\
-\end{array}$ & $\begin{array}{l}- \\
- \\
-\end{array}$ & $\begin{array}{l}1 \\
1.127[0.750,1.693] \\
0.932[0.583,1.488]\end{array}$ & $\begin{array}{l}1 \\
0.984[0.624,1.550] \\
0.863[0.517,1.439]\end{array}$ \\
\hline $\begin{array}{l}\text { Source of } \\
\text { drinking } \\
\text { water } \\
\text { Improved } \\
\text { unimproved }\end{array}$ & - & - & - & $\begin{array}{l}1 \\
0.733^{* * *} \\
{[0.580,0.926]}\end{array}$ \\
\hline $\begin{array}{l}\text { Type of toilet } \\
\text { Improved } \\
\text { Unimproved }\end{array}$ & - & - & - & $\begin{array}{l}1 \\
1.383^{* *} \\
{[1.075,1.777]} \\
\end{array}$ \\
\hline $\begin{array}{l}\text { Floor } \\
\text { material } \\
\text { Improved } \\
\text { Unimproved }\end{array}$ & - & - & - & $\begin{array}{l}1 \\
1.265^{*}[0.988,1.619]\end{array}$ \\
\hline
\end{tabular}

OR - odds ratio; CI - Confidence Interval in square brackets; ${ }^{* * *}-p<0.01 ;{ }^{* *}-p<0.05 ;^{*} p<0.10$

\section{DISCUSSION}

The pooled prevalence of diarrhoea among children aged o-23 months was 18 per cent. Findings from the study showed that some maternal and child factors were significantly associated with childhood diarrhoea. These factors identified include age of child, maternal education, place of residence, source of drinking water, type of toilet facility and type of floor material.

In this study, children who were aged 6-11 and 12-23 months had higher episodes of diarrhoea. This is expected as infants less than six months old may be undergoing exclusive breastfeeding more than those who are older than 6 months. Thus, the latter group is prone to consuming complementary foods; that may contain diarrhoea-causing pathogens (Mihrete et al., 2014; Tambe et al., 2015).

Again, educational status of a mother was associated with childhood diarrhoea. It was observed that children whose mothers had secondary or tertiary education were less likely to have episodes of diarrhoea. More so, those who had secondary or tertiary education exhibited a higher shielding effect against the manifestation 
of childhood diarrhoea. This suggests that, as maternal educational levels increase the less likely it is for their children to experience diarrhoea. The ability to read and understand or hear and appropriately apply information are, perhaps, key for mothers to better cater for their children. As indicated by related literature, maternal education is a predictor of diarrhoea among children (Kumi-Kyereme \& Amo-Adjei, 2016; Mihrete et al., 2014).

Moreover, the environment (an urban area or a rural setting) in which children live could predispose them to some morbidity. Place of residence was found to be significantly associated with diarrhoea in this study. In terms of the occurrence of diarrhoea, children in rural areas had much of the burden. For instance, the consumption of contaminated foods, drinking of unimproved water, poor handling of water, poor socio-economic status, lack of proper sanitation and poor hygiene are some factors deemed to individually or collectively contribute to higher prevalence of diarrhoea in rural environments (Pruss-Ustun et al., 2014). Although, diarrhoea cases are common in urban areas especially in urban slums, children in rural areas are more disadvantaged (Kumi-Kyereme \& Amo-Adjei, 2016). Most rural areas in Ghana are noted for unfavourable health and environmental conditions and are also associated with cultural beliefs that may act as agents for frequent occurrence of childhood diarrhoea (Mengistie et al., 2013; Siziya et al., 2013).

Also, preceding birth interval was found to be significantly associated with childhood diarrhoea. In instances where a mother has two or more children less than two years, the appropriate time needed to cater for each child would be limited. This could alter their feeding patterns and some may stray to eating other unwholesome foods or putting dirty stuff into their mouths that may result in diarrhoea. It has been documented that children with a previous birth interval of less than 18 months have a higher risk of dying from certain causes of death, including sepsis and diarrhoea than children with a previous birth interval of 24-35 months (Rasooly et al., 2013). However, the finding of this study was rather intriguing. Mothers with 24 months or more reported higher odds of childhood diarrhoea. This warrants for future studies to be conducted on preceeding birth interval and episodes of diarrhoea.

In Ghana, about three million people do not have access to improved drinking water (Safe Water Network, 2017). Approximately, 1000 under five child mortalities are due to diarrhoeal diseases caused by poor water and sanitation (WHO, 2019). It was found that source of drinking water used by mothers statistically contributed to childhood diarrhoea. Unimproved sources of water that are mostly contaminated contribute to a high propensity of exposing children to diarrhoeal morbidity. Unexpectedly, this study showed that children whose mothers had access to 
unimproved sources of water were less likely to have had diarrhoea. This probably could be attributed to poor handling and storing of improved sources of water. Contrary to the present finding, elsewhere, studies have found that the use of unimproved source of drinking water is associated with diarrhoea among children (Hunter et al., 2013; Plate et al., 2004). Education on the provision and how to proper handle and store improved sources of drinking water are imperative to reducing the occurrence of diarrhoea among children.

Further the findings revealed an association between type of toilet facility and the occurrence of diarrhoea. Children whose mothers had access to unimproved toilet facilities were more likely to have had episodes of diarrhoea compared to those with improved facilities. The design of improved toilet facilities lessens the spread of diarrhoeal disease pathogens by flying or crawling insects and human contacts (Carr, 2001). The usage of unimproved types of toilet facilities has been found to record higher prevalence of childhood diarrhoea (Mohammed \& Zungu, 2016).

The possibility of children experiencing diarrhoea was higher among those whose house floors were made of unimproved materials compared to their counterparts with improved floor materials. As children crawl or walk about within houses, they at times get to contact with contaminated objects especially within surroundings with poor building materials. This is peculiar with children less than two years who may pick and put most items either food or playing objects into their mouths. And in houses with unimproved floor material are used, the likelihood of oral contacts with contaminated objects or items are relatively higher (Bado et al., 2016).

\section{CONCLUSIONS}

The study was conducted using pooled data from three survey years (2003, 2008, 2014) of GDHS to cross-sectionally analyse the prevalence of childhood diarrhoea. Based on the findings, it can be argued that age of child, maternal education, place of residence, preceding birth interval, source of drinking water, type of toilet, and floor type have effects on the occurrence of diarrhoea among children less than two years in Ghana. To curtail the episodes of diarrhoea among children in the country, health concerned organizations such as Ghana Health Service need to put up more educative programmes targeted towards mothers whose children are much prone to experiencing diarrhoea.

\section{Policy Implications}

The findings of this study suggest occurrence of childhood diarrhoea are linked with some socio-demographic, health and environmental factors. Importantly, 
children whose mothers used improved sources of water, and those with preceding birth interval of 24 months or more were more likely to experience diarrhoea. These findings contradict with related arguments documented by most studies. Policies are required to be innovative, and all inclusive with programmes designed to target specific households or mothers who use various sources of water. Interventions should equally give equal attention to mothers with preceding birth intervals of 24 months or more in Ghana.

\section{Limitations of the Study}

This study has some limitations. Due to the cross-sectional nature in which the data was collected, it means that the results cannot be interpreted in terms of causality. The findings only show possible associations between the dependent variable and independent variables. Also, mothers reported the occurrence of diarrhoea based on two weeks prior to the surveys. This could result in some bias in reporting. Thus mothers might had either over-estimated or under-estimated the episodes of diarrhoea among their children.

\section{ACKNOWLEDGEMENTS}

I thank Measure DHS for the data sets used for analysis. I would also thank Prof. Akwasi Kumi-Kyereme and Dr. Joshua Amo-Adjei (both of the Department of Population and Health, University of Cape Coast, Ghana) for their supportive review comments towards the write-up of this paper.

\section{DECLARATIONS}

Funding: The author did not receive any form of funding to conduct this research.

Conflict of interest: There is no potential conflict of interest.

Ethical approval: The Ghana Health Service Ethics Review Committee approved the surveys from which data for this paper were obtained. Besides, Measure DHS approved a concept note before the datasets were downloaded. Also, more about the sample procedures used in the GDHS are available at http://www.dhsprogram.com/ publications/publication-FR307-DHS-Final-Reports.cfm. 


\section{References}

Agustina, R., Sari, T.P., Satroamidjojo, S., Bovee-Oudenhoven, I.M, Feskens E.J., and Kok F. J. (2013). Association of food-hygiene practices and diarrhoea prevalence among Indonesian young children from low socioeconomic urban areas. BMC Public Health, 13(1), pp. 1-12.

Ameyaw, R., Ameyaw, E., Acheampong, A.O., and Appiagyei, P. (2017). Diarrhoea among Children Under Five Years in Ghana. Global Journal of Research and Review, 4(2), pp. 1-5.

Aziz, E.A.A., Ahmad, N.A., Abdul Razak, M.A., Omar, M., Kasim, N.M., Yusof, M., Sooryanarayana, R., Jamaludin, R., and Ying, C.Y. (2018). Prevalence of and factors associated with diarrhoeal diseases among children under five in Malaysia: a cross-sectional study. BMC Public Health, 18(1363), pp. 1-8.

Bado, A.R., Susuman, A.S., and Nebie, E.I. (2016). Trends and risk factors for childhood diarrhoea in sub-Saharan countries (1990-2013): Assessing the neighborhood inequalities. Global Health Action, 9(30166), pp. 1-12.

Boschi-Pinto, C., Velebit, L., and Shibuya, K. (2008). Estimating child mortality due to diarrhoea in developing countries. Bulletin of the World Health Organization, 86, pp. 710-717.

Carr R. (2001). Excreta-related infections and the role of sanitation in the control of transmission. Water Quality: Guidelines, Standards and Health. IWA Publishing, London, UK.

Degebasa, M.Z., Weldemichael, D.Z. and Marama, M.T. (2018). Diarrheal status and associated factors in under five years old children in relation to implemented and unimplemented community-led total sanitation and hygiene in Yaya Gulele in 2017. Pediatric health, medicine and therapeutics, 9, pp. 109-121.

Exum, N. G. (2016). Beyond diarrhoea: fecal-oral pathogen transmission and environmental enteropathy in Iquitos, Peru. Unpublished doctoral thesis. Johns Hopkins University. Maryland, USA.

Florey, L. and Taylor, C. (2016). Using household survey data to explore the effects of improved housing conditions on malaria infection in children in sub-Saharan Africa. DHS Analytical Studies No. 61. Rockville, Maryland, USA: ICF International

Fotso, J.C., Cleland, J., Mberu, B., Mutua, M. and Elungata, P. (2013). Birth spacing and child mortality: an analysis of prospective data from the Nairobi urban health and demographic surveillance system. Journal of Biosocial Science, 45(6), pp. 779-798. 
Gebru, T., Taha, M. and Kassahun, W. (2014). Risk factors of diarrhoeal disease in under-five children among health extension model and non-model families in Sheko district rural community, Southwest Ethiopia: comparative crosssectional study. BMC Public Health, 14(395), 1-6.

Gedefaw, M. and Berhe, R. (2015). Determinates of childhood pneumonia and diarrhea with special emphasis to exclusive breastfeeding in North Achefer District, Northwest Ethiopia: A case control study. Open Journal of Epidemiology, 5, pp. 107-112.

Getachew, A., Guadu, T., Tadie, A., Gizaw, Z., Genrehiwot, M., Cherkos, D.H., Menberu, M.A. and Gebrecherkos, T. (2018). Diarrhoea prevalence and sociodemographic factors among under-five children in rural areas of North Gondar Zone, Northwest Ethiopia. International Journal of Pediatrics, 6031594, pp. 1-8.

Ghana Statistical Service (2019). Ghana Fact Sheet: People and Society. Retrieved from http://www.statsghana.gov.gh/ghfactsheet.php

Ghana Statistical Service (GSS), Ghana Health Service (GHS) and ICF Macro. (2009). Ghana Demographic and Health Survey 2008. Accra, Ghana: GSS, GHS, and ICF Macro.

Ghana Statistical Service (GSS), Ghana Health Service (GHS) and ICF International. (2015). Ghana Demographic and Health Survey 2014. Accra, Ghana: GSS, GHS, and ICF International.

GHS (2016). Under Five's Child Health Policy. Retrieved from https://extranet.who.int/ nutrition/gina/en/policies/1440

GHS (2018). The health sector in Ghana; Facts and Figures. Retrieved from https://www. ghanahealthservice.org/ghs-item-details.php?cid=5\&scid=55\&iid=128

Hashi, A, Kumie, A. and Gasana, J. (2016). Prevalence of diarrhoea and associated factors among under-five children in Jigjiga District, Somali Region, Eastern Ethiopia. Open Journal of Preventive Medicine, 6, pp. 233-246.

Hill, K. (2003). Frameworks for studying the determinants of child survival. Bulletin of the World Health Organisation, 81(2), pp. 138-139.

Hunter, P. R., Risebro, H., Yen, M., Lefebvre, H., Lo, C., Hartemann, P., Longuet, C., and Jaquenoud, F. (2013). Water source and diarrhoeal disease risk in children under five years old in Cambodia: a prospective diary based study. BMC Public Health, 13(1145), pp. 1-9.

Kumi-Kyereme, A. and Amo-Adjei, J. (2016). Household wealth, residential status and the incidence of diarrhoea among children under-five years in Ghana. Journal of Epidemiology and Global Health, 6, pp. 131-140. 
Lamberti, L.M., Walker, C.L.F., Noiman, A., Victora, C. and Black, R.E. (2011). Breastfeeding and the risk of diarrhoea morbidity and mortality. BMC Public Health, 11(15), pp. 1-12.

McGlynn, N., Wilk, P., Luginaah, I., Ryan, B.L. and Thind, A. (2015). Increased use of recommended maternal health care as a determinant of immunization and appropriate care for fever and diarrhoea in Ghana: an analysis pooling three demographic and health surveys. Health Policy and Planning, 30, pp. 895-905.

Mengistie, B., Berhane, Y. and Worku, A. (2013). Prevalence of diarrhoea and associated risk factors among children under-five years of age in Eastern Ethiopia: A cross-sectional study. Open Journal of Preventive Medicine, 3, pp. 446-453.

Mihrete, T.S., Alemie, G.A. and Teferra, A.S. (2014). Determinants of children diarrhea among under-five children in Benishangul Gumuz Regional State, North West Ethiopia. BMC Pediatrics, 14(102), pp. 1-9.

Mohammed, A. and Zungu, L. (2016). Environmental health factors associated with diarrhoeal diseases among under-five children in the Sebeta town of Ethiopia. Southern African Journal of Infectious Diseases, 31(4), pp. 122-129.

Mosley, W. H. and Chen, L. C. (2003). An analytical framework for the study of child survival in developing countries. 1984. Bulletin of the World Health Organisation, 81(2), pp. 140-145.

Pathela, P., Hasan, K.Z., Roy, E., Huq, F., Siddique, A.K. and Sack, R.B. (2006). Diarrhoeal illness in a cohort of children o-2 years of age in rural Bangladesh: Incidence and risk factors. Acta Padiatrica, 95, pp. 430-437.

Pinzon-Rondon, A.M., Zarate-Ardila, C., Hoyos-Martinez, A., Ruiz-Sternberg, A.M. and Velez-van-Meerbeke, A. (2015). Country characteristics and acute diarrhea in children from developing nations: a multilevel study. BMC Public Health, 15(811), pp. 1-11.

Pirincci, E., Tasdemir, R. and Oguzoncul, A.F. (2016). Knowledge of lactational amenorrhoea as a contraceptive method among mothers of infants aged o-6 months in a district, Eastern Turkey. International Journal of Community Medicine and Public Health, 3(6), pp. 1363-1370.

Plate, D.K., Strassmann, B.I. and Wilson, M.L. (2004). Water sources are associated with children diarrhoea prevalence in rural east-central Mali. Tropical Medicine International Health, 9(3), pp. 416-25.

Pruss-Ustun, A., Bartram, J., Clasen, T., Colford, J., Cumming, O., Curtis, V., Bonjour S., Dangour, A.D., France, J.D., Fewtrell, L., Freeman, M.C., Gordon, B., Hunter, P.R., Johnston, R.B., Mathers, C., Mausezahl, D., Medlicott, K., Neira, M., Stocks, M., Wolf, J. and Cairncross, S. (2014). Burden of disease from inadequate water, 
sanitation and hygiene in low - and middle-income settings: a retrospective analysis of data from 145 countries. Tropical Medicine and International Health, 19(8), pp. 894-905.

Rasooly, M.H., Saeed, K.M.I., Noormal, B., Aman, I., Arnorld, F., Govindasamy, P., Rutstein, S. and Winter, R. (2013). The effectives of birth intervals on causes of under-five mortality in Afghanistan. DHS Working Paper, Measure DHS, ICF International

Safe Water Network. (2017). Access to safe water: Ghana. Available from http://www. safewaternetwork.org/countries-regions/ghana. Retrieved from

Siziya, S., Muula, A.S. and Rudatsikira, E. (2013). Correlates of diarrhoea among children below the age of 5 years in Sudan. African Health Sciences, 13(2), pp. 376-383.

Stanly, A.M., Sathiyasekaran, B.W.C. and Palani, G. (2009). A population based study of acute diarrhoea among children under 5 years in a rural community in South India. Sri Ramachandra Journal of Medicine, 1(1), pp. 1-7.

Tambe, A.B., Nzefa, L.D. and Nicoline, N.A. (2015). Childhood diarrhea determinants in sub-Saharan Africa: A cross sectional study of Tiko-Cameroon. Challenges, 6, pp. 229-243.

Thiam, S., Diene, A.N., Fuhrimann, S., Winkler, M.S., Sy, I., Ndione, J.A., Schindler, C., Vounatsou, P., Utzinger, J., Faye, O., and Cisse, G. (2017). Prevalence of diarrhoea and risk factors among children under five years old in Mbour, Senegal: a cross-sectional study. Infectious Diseases of Poverty, 6(109), pp. 1-12.

United Nations [UN]. (2016). Sustainable Development Goals: Goal3-Ensure healthy lives and promote well-being for all at all ages. Retrieved from http://www.un.org/ sustainabledevelopment/health/

United Nations Children's Education Fund [UNICEF]. (2015). Breastfeeding: Impact on child survival and global situation. Retrieved from http://www.unicef.org/ nutrition/index_24824.html.

UNICEF and World Health Organization [WHO]. (2009). Diarrhoea: Why children are still dying and what can be done. WHO Press, Geneva, Switzerland.

WHO \& UNICEF. (2013). Ending Preventable Child Deaths from Pneumonia and Diarrhoea by 2025: The integrated Global Action Plan for Pneumonia and Diarrhoea. Retrieved from http://www.who.int/maternal_child_adolescent/documents/global_ action_plan_pneumonia_diarrhoea/en/ 
WHO. (2009). Diarrhoea: why children are still dying and what can be done. Retrieved from http://www.who.int/maternal_child_adolescent/documents/9789241598415/ en/.

WHO. (2016). WHO recommendations on antenatal care for a positive pregnancy experience. WHO Press, Geneva, Switzerland.

WHO \& UNICEF. (2009). Joint Monitoring Programme for Water Supply, Sanitation and Hygiene. Retrieved from http://www.unwater.org/publication_categories/ whounicef-joint-monitoring-programme-for-water-supply-sanitationhygiene-jmp/.

WHO. (2015). Global Health Observation (GHO) data: Causes of child mortality. 2015. Retrieved from http://www.who.int/gho/child_health/mortality/causes/en/.

WHO. (2019). Sanitation and Health. Retrieved from https://www.who.int/newsroom/fact-sheets/detail/sanitation 